\title{
A ECOLOGIA DE ASSENTAMENTOS, INTERAÇÕES SOCIAIS AMERÍNDIAS E O CONTEXTO GEOGRÁFICO DOS MUIRAQUITÃS NO BAIXO AMAZONAS.
}

THE ECOLOGY OF SETTLEMENTS, AMERINDIANS SOCIAL INTERACTIONS AND THE GEOGRAPHICAL CONTEXT OF MUIRAQUITÃS IN THE LOW AMAZONAS.

\author{
Anderson Márcio Amaral Lima
}

Como citar este artigo:

LIMA, Anderson Márcio Amaral. A Ecologia de Assentamentos, Interações Sociais Ameríndias e o Contexto Geográfico dos Muiraquitãs no Baixo Amazonas.In: Cadernos do Lepaarq, v. XV, n.30., p. 121-141, Jul-Dez. 2018. 


\title{
A Ecologia de Assentamentos, Interações Sociais Ameríndias e o Contexto Geográfico dos Muiraquitãs no Baixo Amazonas.
}

\author{
Anderson Márcio Amaral Lima*
}

Resumo: Este artigo aborda a importância da paisagem e as correlações entre ecologia de assentamentos humanos e a construção do tecido social entre sociedades ameríndias no período pré-colonial e colonial, no baixo Amazonas, precocemente fomentadas pelas redes de troca. Nas crônicas ibéricas sobre o Rio das Amazonas, dos séculos XVI e XVII, são mencionados aspectos relacionados à paisagem cultural de Santarém, tida como o centro político dos Tapajós, em uma extensa área entre os municípios de Juruti e Prainha. Microrregiões do oeste paraense, que estavam politicamente integradas por sistemas de chefias regionais, foram nomeadas de província de São João, por Gaspar de Carvajal. Trata-se da mesma área das províncias arqueológicas de Santarém-Nhamundá-Trombetas, historicamente vinculadas como centros de produção e circulação de objetos de pedras verdes, conhecidos como muiraquitãs.

\section{Palavras Chave:}

Santarém; Muiraquitãs; Rio Tapajós.

\begin{abstract}
This article discusses the importance of landscape and the correlations between ecology of human settlements and the construction of the social tessitura between Amerindian societies in the pre-colonial and colonial times in the lower Amazonas, precocious fomented by the exchange networks. In the Iberian chronicles on the River of the Amazons of the sixteenth and seventeenth centuries, aspects related to the cultural landscape of Santarém, considered as the political center of the Tapajós Indians, and of an extensive area between the municipalities of Juruti and Prainha, microregions of western Paraense, that were politically integrated, by systems of regional heads, being named of province of São João by Gaspar Carvajal. It is the same area of the archaeological provinces of Santarem-NhamundáTrombetas, historically linked as centers of production and circulation of objects of green stones known as muiraquitãs.
\end{abstract}

Keywords:

Santarém; Muiraquitãs; Tapajós River. 


\section{ÁREA SANTARÉM, ANTIGO POLO CULTURAL AMERÍNDIO NO BAIXO AMAZONAS.}

\section{Em memória de Denise Schaan.}

Nas terras baixas amazônicas e em outras partes da América do Sul, a pesquisa arqueológica, nas últimas décadas, tem voltado seu interesse para o paradigma da construção da paisagem e o encadeamento da tessitura social, fomentada pelas antigas redes de interações ameríndias de curta, média e longa distância (BALÉE, 1989, 2017; ANCHUERTZ, et, al 2001; STENBORG, et al., 2012; CLEMENT e FREITAS, 2013; ROSTAIN, 2014a e b).

Na região de Santarém, antigo polo cultural ameríndio no Baixo Amazonas, os dados disponíveis apontam que, desde o Pleistoceno final e o Holoceno inicial, o ambiente vem passando por modificações constantes, causadas por fatores geológicos, hidrológicos e climatológicos (IRION, et. al. 2006). Na transição Pleistoceno-Holoceno, uma nova ordem de mudanças ambientais toma início na Amazônia, não produzidas por fenômenos naturais, mas como resultado direto de interferência humana nas paisagens (ROOSEVELT et. al. 1996). Persistentes na longa duração, as mudanças antrópicas na região do Baixo Amazonas foram intensificadas no pré-colonial tardio, resultando em mudanças substanciais na ecologia da paisagem e demografia das plantas (SHOCK, et. al,. 2014; ALVES, et al.,2016). A relativa uniformidade da floresta ombrófila equatorial, em primeiro olhar, faz com que essa diferenciação entre o natural e o antrópico caminhe por tênues linhas paralelas, dificultando uma melhor avaliação por parte do pesquisador (BALÉE, 1993; MAZZ, et. al, 2016). Todavia, é de vital importância o reconhecimento da paisagem cultural e das correlações na longa duração entre a ecologia de assentamentos e o fomento precoce do tecido social entre sociedades ameríndias amazônicas (HECKENBERGER, et, al. 2008).

Nas crônicas ibéricas dos séculos XVI e XVII (CARVAJAL. 1941:11 HERIARTE, 1874:35-39; BETENDORF, 1910:59) são mencionados aspectos relacionados à paisagem cultural de Santarém, tida como o centro político dos Tapajós, e de uma extensa área entre os municípios de Juruti e Prainha, microrregiões do Oeste Paraense, que estavam politicamente integradas por sistemas de chefias regionais e foram nomeadas conjuntamente de província de São João (CARVAJAL, 1941:79). O primeiro registro que se conhece sobre a ecologia de assentamentos em Santarém está contido no relato do frade dominicano Gaspar de Carvajal (CARVAJAL, 1941:11-79; AMARAL, 2004:3). Cronista da expedição de Francisco de Orellana, não menciona nada acerca da urbe que seria o centro político da chefia tapajônica, espraiada nas areias da margem direita junto, à foz do rio Tapajós. Contudo, o cronista nos fornece um quadro geral da paisagem cultural na área Santarém, condizentes com topografia, distância, cobertura vegetal e padrão de ocupação humana das margens do rio Tapajós às bordas das serras, localizadas ao sul de Santarém (Piquiatuba, Mararú, Ipanema e Diamantino). Segundo Carvajal, "por toda aquela margem direita que é o lado sul, para o interior a umas duas léguas mais ou menos, aparecia grandes cidades que estavam alvejando [...]" (CARVAJAL 1941: 11). Seguindo na leitura do autor, "a terra é alta e fazem lombas, todas de savanas com ervas que chegam aos joelhos [...]. Os montes destas terras, são azinhais, sorverais, com bolotas [Couma utiliss.?] porque nós as vimos e carvalhais" (CARVAJAL 1941: 79).

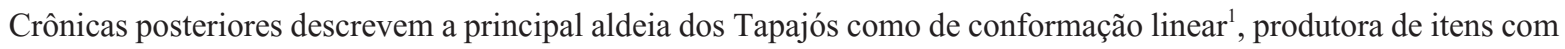
alta valoração simbólica e situada na grande enseada que começa logo após o morro da Fortaleza, estendendo-se em direção ao Sítio Porto de Santarém (BERREDO, 1749:733; BETENDORF, 1910:59; HERIARTE, 1874:35). Recentemente, as in-

1 O sítio arqueológico urbano de Santarém, de conformação linear, situa-se em uma comunidade ecológica diferenciada das áreas do Planalto Santareno/Belterrense, que apresenta em suas bordas um padrão de ocupação muito similar ao descritos para os barrancos às margens do rio Amazonas (CARVAJAL, 1941; DENEVAN, 1996; AMARAL, 2004). 
formações históricas relacionadas à produção de itens específicos da cultura material dos Tapajós foram corroboradas pelo registro arqueológico, certificando que no sítio arqueológico Urbano de Santarém funcionavam oficinas líticas e suas cadeias operatórias de produção de muiraquitãs (HERIARTE, 1874:37; MORAES, et, al. 2014, AMARAL, 2017).

\section{O ENTRECRUZAMENTO DE ECOTONOS NA EMBOCADURA DO RIO TAPAJÓS E A TESSITURA SOCIAL NA LONGA DURAÇÃO}

Para um melhor entendimento sobre como as paisagens foram construídas em um ambiente tão heterogêneo, é importante lembrar que na embocadura do rio Tapajós e nos arredores de Santarém a paisagem apresenta singularidades geomorfológicas e bióticas que se entrecruzam no entorno da confluência deste com o Amazonas. Segundo os levantamentos geológicos realizados na região do Baixo Tapajós, a geomorfologia local é caracterizada por apresentar quatro unidades morfoestruturais bem definidas e vegetação, por sua vez, composta por quatro formações florestais bem distintas: floresta equatorial subperenifólia e cerrado equatorial subperenifólio, na terra firme; e floresta equatorial higrófila de várzea e campos equatoriais higrófilos de várzea (RADAMBRASIL, folha 21, 1976; RODRIGUES, et, al. 2001; ROCHA, 2014).

A junção de comunidades ecológicas distintas às proximidades do baixo rio Tapajós ocasionou um complexo e dinâmico sistema em constante transformação, influenciado por fatores de ordem climatológica, geológica e hidrológica (IRION, et. al. 2006; FARIAS, 2012) que, associados a mudanças antrópicas milenares, produziram alterações significativas nas paisagens do local onde estava assentado o antigo centro político dos Tapajós e de centenas de aldeias que orbitavam sob sua influência (BETENDORF, 1910; NIMUENDAJÚ, 1949, 1952, 1953; STENBORG et. al., 2010, 2012).

\section{A CAPINARANA}

A capinarana ${ }^{2}$, ou cerrado equatorial subperenifólio (Fig.1), compõe a cobertura vegetal original dos terrenos arenosos amazônicos. Aparentemente, no Holoceno, a faixa arenosa foi um dos locais escolhidos no Baixo Amazonas por grupos humanos, que se fixaram de forma semissedentária ou sedentária, manejando o solo pobre em nutrientes. Isso pode ter sido um gatilho nos processos de antropização e de domesticação, que resultaram nas grandes áreas de terra preta arqueológica (TPA) de consistência arenosa, as quais são encontradas nos arredores de Santarém e nas margens do rio Tapajós.

No século XIX, cientistas naturalistas, em trabalhos de campo nos arredores da cidade, identificaram involuntariamente um padrão distribuído pela faixa arenosa de antigas aldeias de formato circular ${ }^{3}$ que eram conhecidas pelos locais como capões ou ilhas de mato (Fig. 2 e 3). As ilhas de mato e o cinturão verde do sítio arqueológico urbano de Santarém foram descritos como de vegetação composta por árvores de grande porte entrelaçadas por lianas. Contrapondo a faixa verde ao fundo, estão as capinaranas e os escaldantes areais, com árvores esparsas de pequeno e médio porte, matas de galeria e gramíneas, sujeitas a incêndios naturais no verão amazônico (BATES, 1979; RODRIGUES, 1889, RODRIGUES, et, al. 2001).

2 Estudos florísticos indicaram uma semelhança entre a vegetação da capinarana e o cerrado do Brasil central, porém com uma menor diversidade de espécies que este último (MIRANDA, et al., 2003). Características do ambiente de Capinarana são drenagem acentuada, umidade variável entre 8 - 12\% no verão e 20 - 25\% no inverno, concentrando baixa carga de nutrientes, um ambiente pouco favorável à produção de alimentos (AMARAL, 2004, RAIMUNDO COSME, informação pessoal).

3 O padrão de aldeias circulares estava inserido na paisagem entre a base das serras que formam o planalto Santareno/Belterrense e as margens do rio Tapajós. Não há estudo ou pesquisa arqueológica sistemática da cultura material ou datações acerca deste padrão de ocupação na faixa arenosa e muitos destes sítios se encontram selados pela sedimentação, abaixo de estruturas em áreas residenciais da moderna Santarém, ou destruídos (AMARAL, 2004).

LIMA, Anderson Márcio Amaral. A Ecologia de Assentamentos, Interações Sociais Ameríndias e...In: Cadernos do Lepaarq, v. XV, n.30., p. 


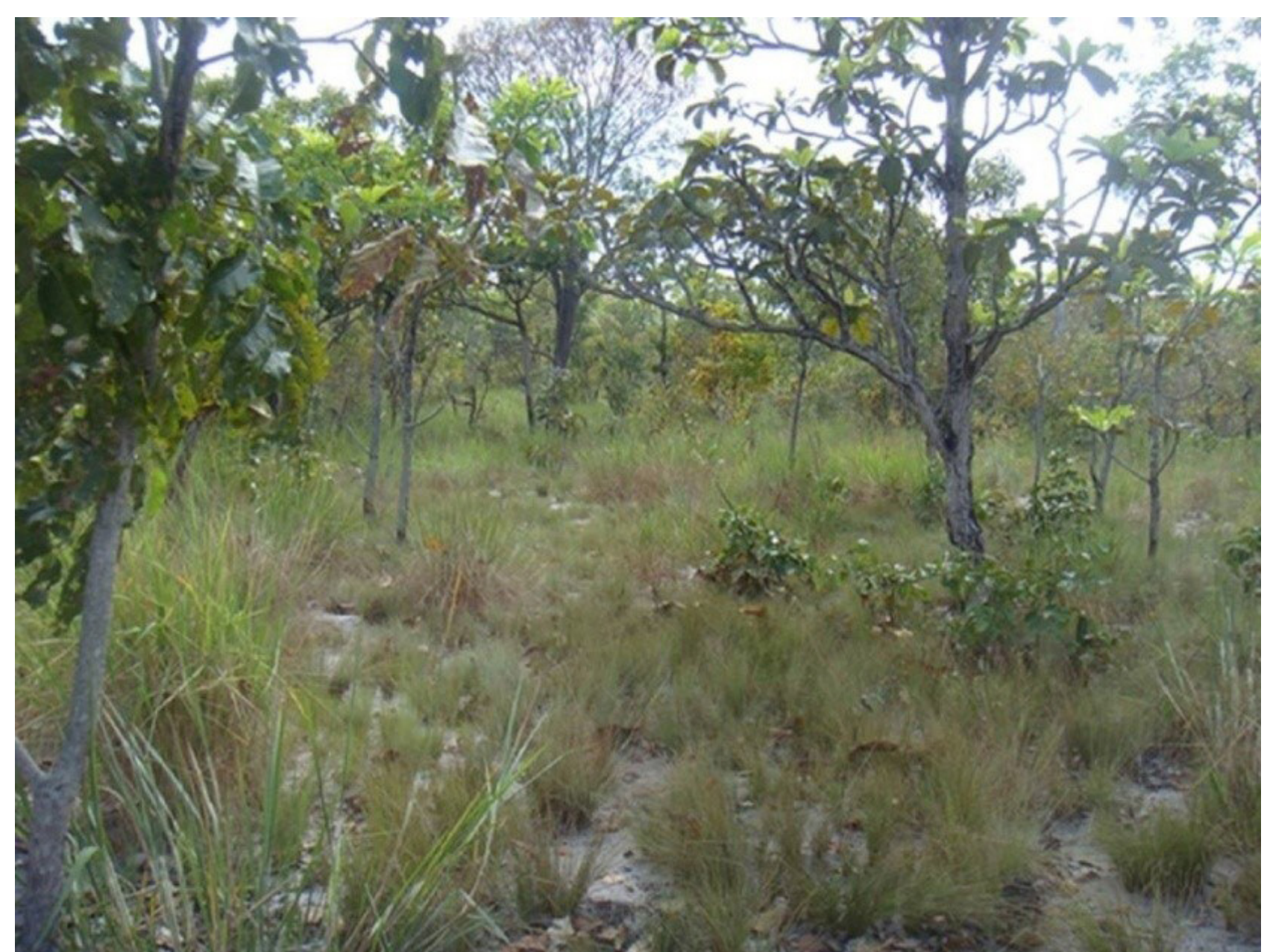

Figura 1 - Sítio arqueológico com cerâmicas Pocó, associado à vegetação de capinarana às margens do rio Tapajós. Foto: Márcio Amaral.

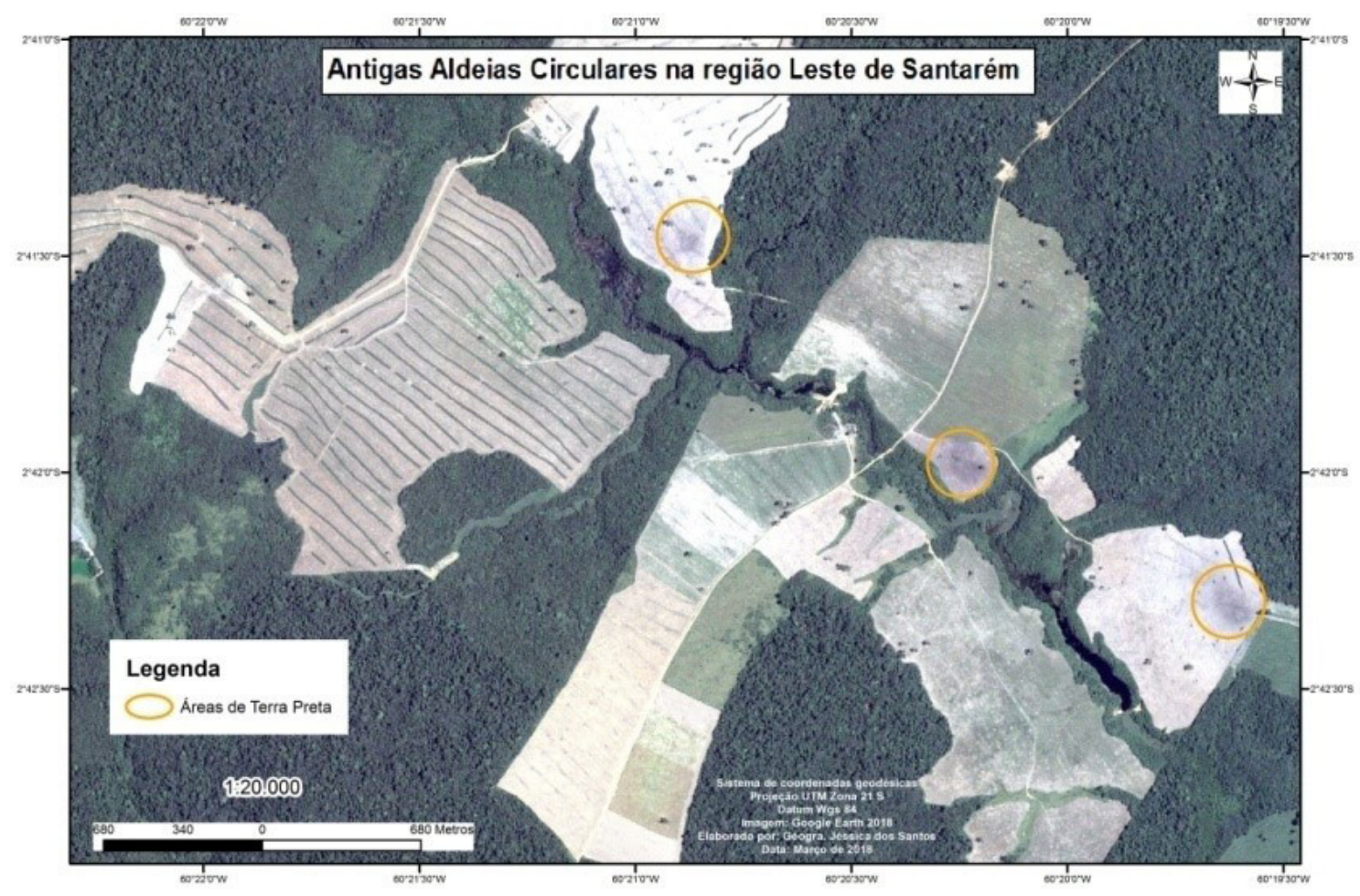

Figura 2 - Sítios arqueológicos de antigas aldeias circulares a leste de Santarém. Mapa elaborado por Jéssica P. G. dos Santos. 


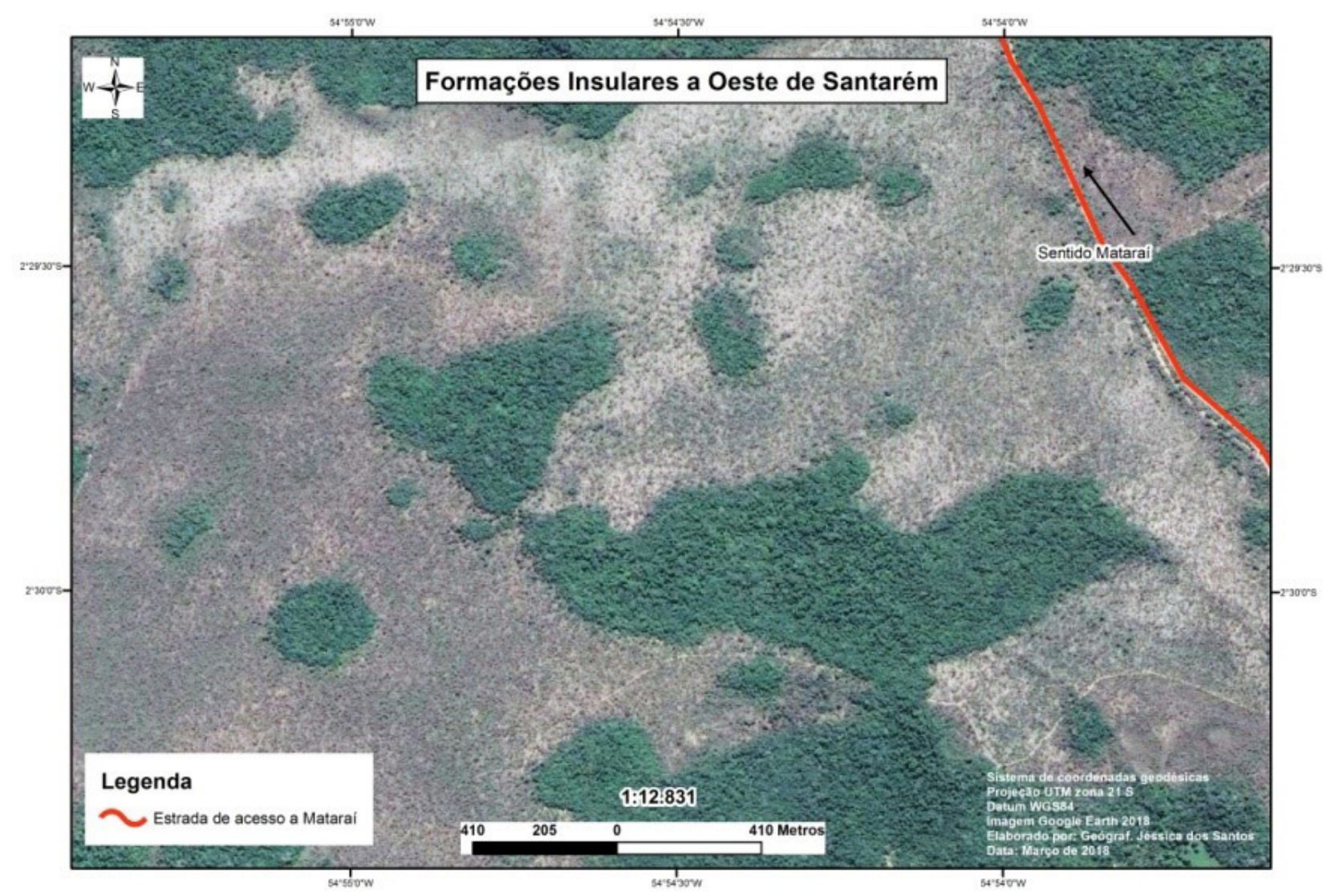

Figura 3 - Formações insulares de vegetação alta, contrastando com áreas de capinarana a oeste de Santarém.

Mapa elaborado por Jéssica P. G. dos Santos

\begin{abstract}
A VÁRZEA
Na porção Norte e Leste/Oeste do município de Santarém, a região de várzea representa uma planície fluvial com depósitos aluviais atuais e subatuais, com predomínio de argilas e areias, levemente alçado à lâmina d'água, com altitudes próximas a 20 metros (OLIVEIRA, et al., 2000 ). A floresta equatorial higrófila de várzea e os campos equatoriais higrófilos de várzeas são as comunidades ecológicas predominantes, cujas áreas, sujeitas a inundações periódicas no inverno amazônico, caracterizam-se pela presença de lagos de formatos arredondados, onde apenas $10 \%$ da cobertura vegetal é constituída por florestas (RODRIGUES, et, al. 2001; ROCHA, 2014; MACGRATH et al.,2000). No contexto geral, as várzeas (Fig. 4) amazônicas eram, e ainda são, de importância estratégica na obtenção de proteína animal e vegetal, com registro de ocupações humanas anteriores ao inicio da invasão europeia, no século XVI (HERIARTE 1874; NIMUENDAJÚ, 1953, DENEVAN, 1996, ROOSEVELT, 1999).
\end{abstract}

Sítios arqueológicos relacionados à cultura Santarém Clássica (Fig.5), com cerâmicas de estilo incisa e ponteada, globular de estilo Santarém, Santarém Modo Pintado ou a fusão dos modos em associação a muiraquitãs diagnósticos, foram registrados em ambientes de várzea, a montante e a jusante de Santarém (NIMUENDAJÚ, 1953; AMARAL, 2016; 2017). 


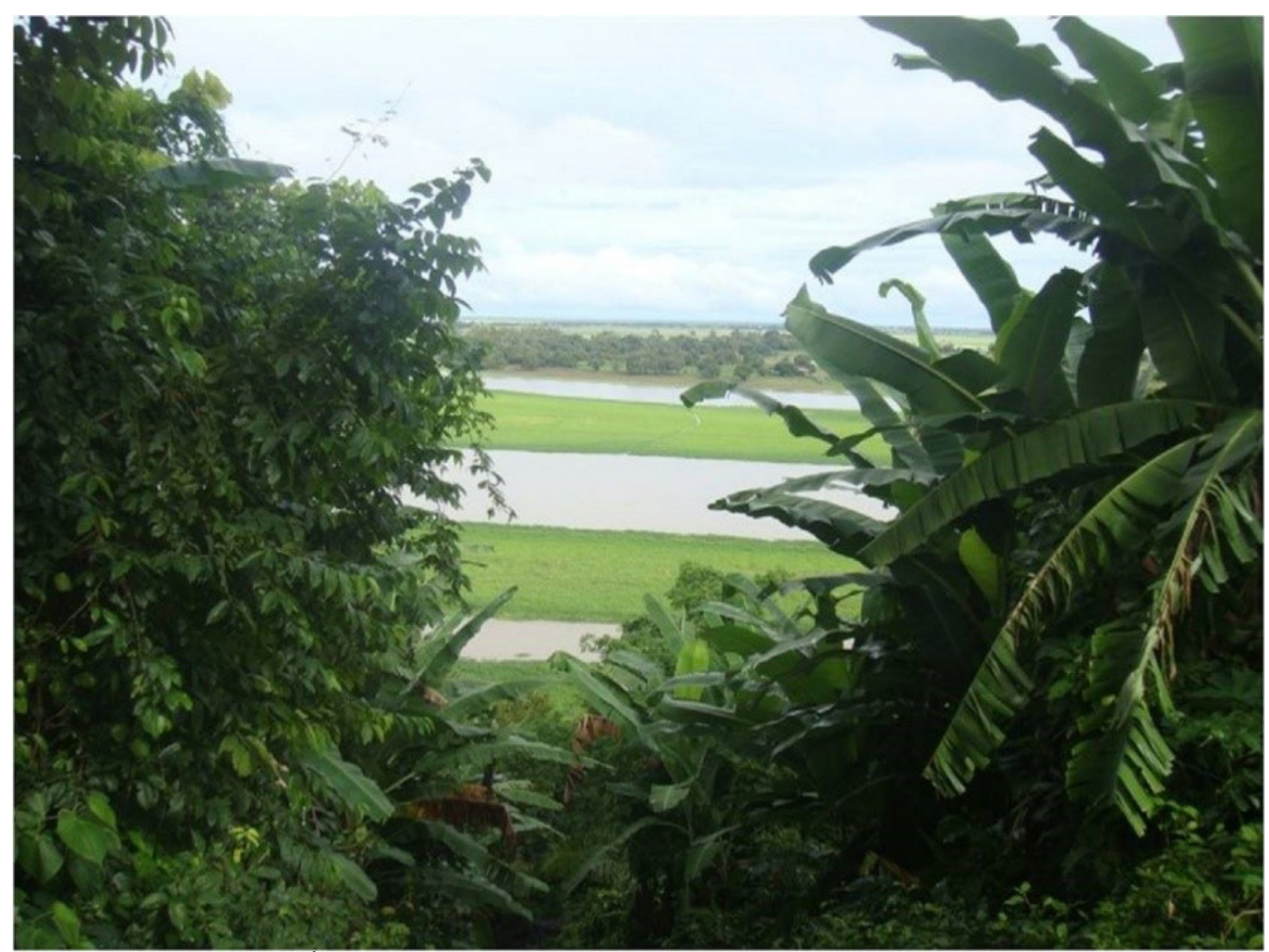

Figura 4 - Áreas de várzea, a montante de Santarém, com vegetação de campos e florestas alagáveis. Foto: Márcio Amaral

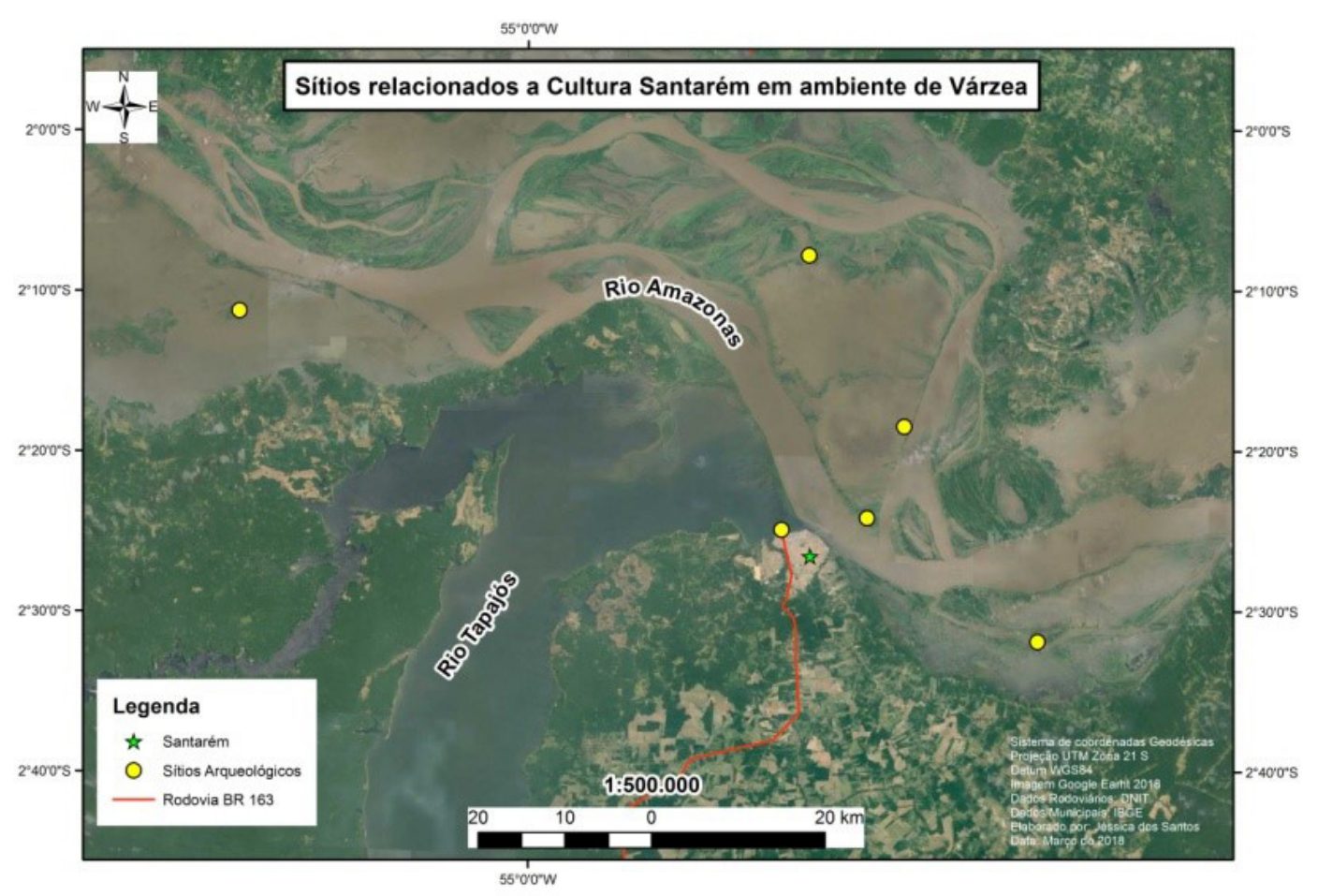

Figura 5 Lagos de várzea ao norte da cidade de Santarém, fonte abundante de proteína animal no verão Amazônico e sítios arqueológicos associados. Mapa elaborado por Jéssica P. G. dos Santos. 


\section{O PLANALTO}

As terras altas ou planalto Santareno/Belterrense, ao sul da cidade de Santarém, apresentam conformação tabular, superfície plana com bordos erosivos e cotas de altimetria que variam de 16 a $250 \mathrm{~m}$ acima do nível médio do mar. A geomorfologia é composta por antigas camadas sedimentares dos períodos Cretáceo-Terciário e Quaternário (RADANBRASIL, 1976; ROCHA, 2014; SCHAAN E AMARAL, 2012) e estudos pedológicos e edafológicos, realizados entre 2005-20134, resultaram em dados que demonstram que os solos nas áreas de planalto são constituídos principalmente por latossolos ${ }^{5}$ e argissolos amarelos que, quando manejados, alcançam alta produtividade (RODRIGUES. et, al. 2001; AMARAL, 2004; STENBORG. et, al. 2012; 2014). Faz parte da cobertura vegetal das áreas de planalto a floresta equatorial subperenifólia, com porções significativas compostas por florestas antrópicas ou manejadas e suas espécies úteis aos seres humanos. Entre os séculos XVI e XIX, a vegetação no planalto ao sul de Santarém era composta por florestas altas manejadas (CARVAJAL, 1941:11; HARTT, 1885:12; NIMUENDAJÚ, 1953:59).

As pesquisas arqueológicas antigas e recentes têm apontado que o planalto Santareno/Belterrense foi grandemente modificado (Fig. 6) no período pré-colonial tardio e colonial pelo adensamento de aldeias em associação a significativas obras de engenharia utilitária, como a construção de estradas interligando margens de rios a conjuntos de aldeias, a escavação de poços com capacidade de armazenagem ampliada pela construção de muros de terra, a impermeabilização e a ampliação de cavidades naturais e de canais de drenagem para o direcionamento das águas pluviais, a construção de plataformas de habitação e de prováveis sítios cerimoniais (NIMUENDAJÚ, 1953; AMARAL, 2004; STENBORG et al., 2012, 2014, 2018). Como resultado, no período entre os séculos XII e XVII da era cristã, uma área com aproximadamente $7.500 \mathrm{~km}^{2}$ foi transformada em paisagem étnica e ritual pela expansão da cultura Santarém Clássica na região do planalto (AMARAL, 2004; SCHAAN E AMARAL, 2012; STENBORG et al., 2012, 2014).

As singularidades na paisagem no baixo Tapajós e o entrecruzamento de comunidades ecológicas junto à sua foz, de maneira oposta àquela postulada pela ecologia cultural, contribuíram para a longa duração do desenvolvimento e da permanência de assentamentos humanos na região. Isso suscita a ideia de que, no período pré-colonial tardio, os Tapajós intensificaram as alterações na paisagem, na região do Baixo Amazonas, empregando estratégias distintas e simultâneas de apropriação, visando à exploração e o gerenciamento de recursos.

Os padrões das ocupações antigas nestas áreas são corroborados por meio das diversas fontes documentais disponíveis, levantamentos sistemáticos de sítios, registros arqueológicos e na relativamente alta quantidade de datações. Sustenta-se que o Baixo Amazonas, em período pré-colonial tardio e colonial, alcançou significativo desenvolvimento sociocultural na forma de apropriação e de alterações substanciais na ecologia das paisagens, de alta demografia, da exploração e do manejo de recursos em grande escala, de indústrias cerâmicas e líticas refinadas, de agricultura, de religião, de redes de trocas e do envolvimento em guerras ${ }^{6}$, em um cenário que propiciou à sociedade tapajônica a construção de um intrincado pano social, intra e extra-área Santarém (ACUNÃ, 1641; HERIARTE, 1884; PORRO, 1992; NEVES, 2009; STENBORG et al. 2012, HARRIS, 2015; ROCHA, 2017).

4 Secretaria Executiva de Estado de Planejamento, Orçamento e Finanças (SEPOF), Cultivated Wilderness Project, Embrapa e produtores independentes de soja e milho.

5 O latossolo da região do Planalto Santareno/Belterrense apresenta textura média, argilosa e muito argilosa 75 -95\%, em associações com solos antrópicos e lateríticos, drenagem 15 - 20\% no verão e 38 - 45\% no inverno, (SEPROF, 2005; AMARAL,2004; SCHAAN E AMARAL, 2012; SODERSTROM et al., 2013, RAIMUNDO COSME, comunicação pessoal)

6 Pesquisas recentes realizadas no planalto Santareno/Belterrense, Lago Grande de Vila Franca e baixo curso do rio Curuá Una, apontam uma expansão da cultura Santarém, apropriação da paisagem e integração em escala macro entre os séculos X e XVII (STENBORG et, al,. 2010; 2012; 2014).

LIMA, Anderson Márcio Amaral. A Ecologia de Assentamentos, Interações Sociais Ameríndias e...In: Cadernos do Lepaarq, v. XV, n.30., p. 


\section{Densidade de Sítios Arqueológicos na região de Lavras do Planalto Santareno/Belterrense}
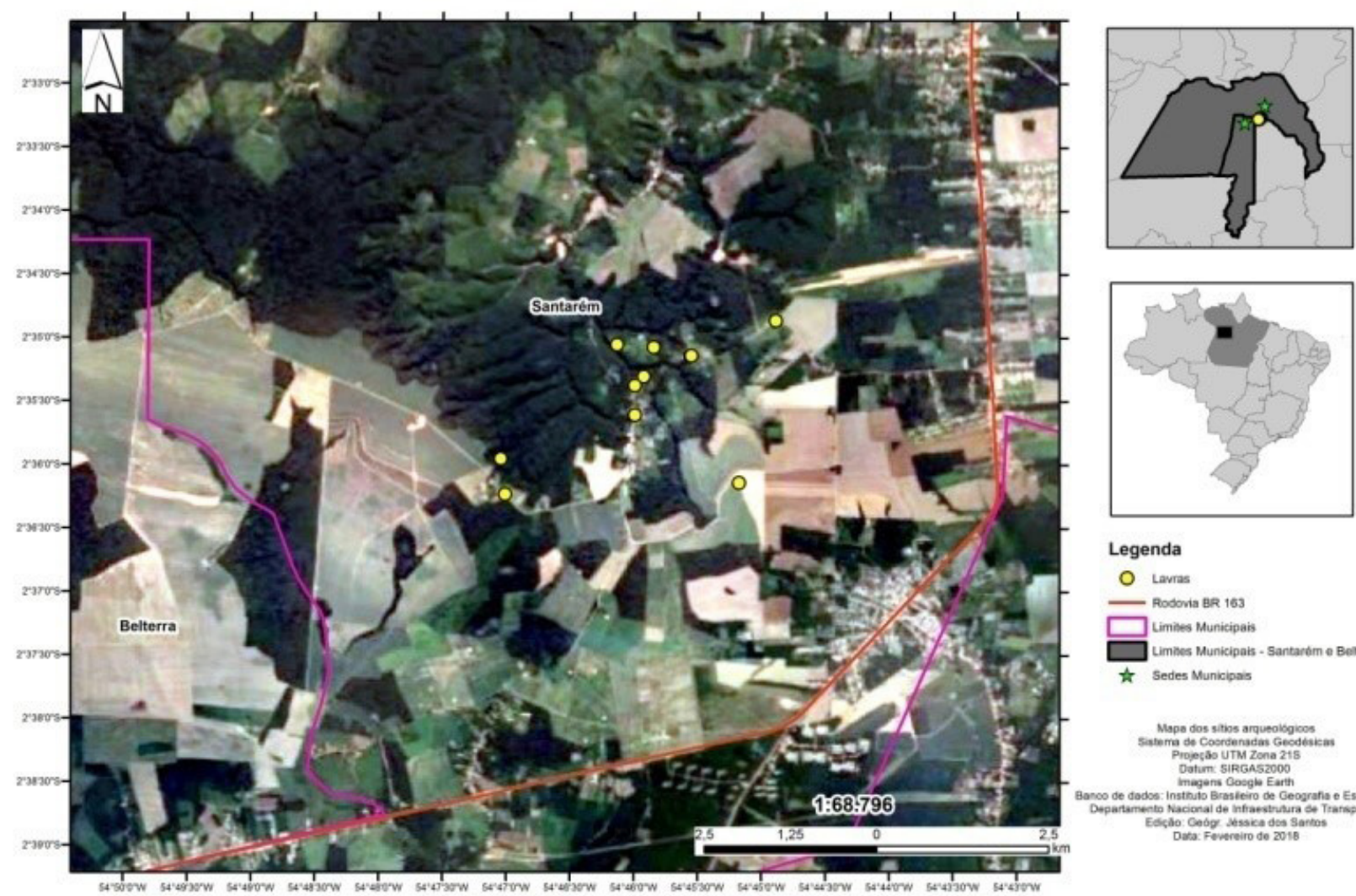

Legenda

O Lavras

- Rodonia BR 163

$\square$ Limies Municipais

t Sedes Municipais

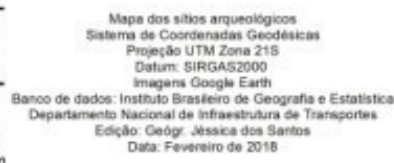

Figura 6 - Adensamento de sítios arqueológicos na Região de Lavras, município de Santarém.

Mapa elaborado por Jéssica P. G. dos Santos.

Decorridos cinco séculos após o início da invasão europeia, malgrada a dinâmica sedimentar do rio Amazonas e a agropecuária extensiva na várzea, o avanço desordenado da urbanidade na faixa arenosa, e o agronegócio ${ }^{7}$ na região de planalto, ainda são perceptíveis as marcas produzidas na paisagem que, longe de ser uma escolha aleatória, era constituída de propósito específico ou associada a fatores demográficos, tecnológicos ou culturais endógenos ou exógenos, surgidos por meio de interações sociais com outros grupos (ANSCHUETZ et, al., 2001; SCHAAN E AMARAL, 2012; ROSTAIN, 2014a e b).

As escolhas para a implantação de assentamentos humanos e determinada área podem ser nominadas de ecologia de assentamentos, paisagens rituais e paisagens étnicas, tendo como propósito favorecer logísticas e demandas, ratificando um profundo conhecimento do ecossistema por partes de populações ameríndias na Amazônia (ANSCHUETZ et, al., 2001). Assim, a pesquisa arqueológica forneceu elementos de planejamento futuro por parte desses coletivos, nas áreas previamente selecionadas. Na atualidade, ainda persiste o antigo costume para a escolha e fixação de assentamentos humanos, onde as cidades e comunidades de origem colonial e os modernos núcleos urbanos estão inseridos na paisagem sob os refugos de antigas aldeias. Fato que demonstra de maneira objetiva que o padrão nas escolhas para fixação humana atual na Amazônia é conexo ao padrão pré-colonial (ROCHA et. al.,2013; ALMEIDA, 2017).

7 A recolonização das áreas de planalto, no século XIX, por quilombolas, confederados estadunidenses, ribeirinhos, cearenses, criação do projeto Belterra, em meados da década de 1930 e abertura da rodovia BR 163 na década 1970 causaram impactos menores quando comparados com a chegada do agronegócio nas últimas duas décadas, que vem destruindo sistematicamente dezenas de depósitos arqueológicos e a floresta antrópica, substituída pela monocultura de soja. 


\section{O SÍTIO ARQUEOLÓGICO URBANO DE SANTARÉM}

A porta de acesso aos antigos padrões de ocupação na Amazônia pode ser aberta por meio de uma abordagem detalhada sobre a paisagem, e sua abordagem é essencial para a compreensão das sociedades ameríndias pré-coloniais. Uma vez que a domesticação da paisagem, ao longo de milênios, produziu, na Amazônia, ambientes carregados de história, em partes erodidos ou preservados e ocultos abaixo dos modernos centros urbanos, dos sedimentos em leitos de rios e lagos ou sob o espesso dossel equatorial em locais pouco acessíveis a pesquisa. Em Santarém, essas histórias passaram a ser interpretadas e contadas pela pesquisa arqueológica e pelas disciplinas associadas, a partir do antigo centro político dos Tapajós (HERIARTE, 1874, NIMUENDAJÚ, 1949, PALMATARY, 1960). Por meio das interfaces geradas entre arqueologia e paisagem, facilitando o reconhecimento das relações dinâmicas e interdependentes que grupos humanos mantinham com as dimensões físicas, sociais e culturais, fornecendo ao pesquisador os referenciais adequados para uma melhor avaliação de paisagens contemporâneas, beneficiando o entendimento da construção e manejo de paisagens pretéritas (ANSCHUETZ et. al., 2001, BALÉE, 2017).

Na região de Santarém, a pesquisa acadêmica tem focado sua atuação na região do planalto Santareno/Belterrense e, principalmente, no sítio arqueológico Urbano de Santarém (Fig. 6), que foi dimensionado com base em dados empíricos, estabelecendo uma zona com paisagem domesticada, a qual engloba nove bairros na área central da cidade, cobrindo uma área superior a 4 km² (AMARAL, 2004-2011). Um gigantesco depósito cultural, que apresenta pontos de floresta antrópica residual e palimpsesto arqueológico com até 2 metros de profundidade, configurando uma das maiores jazidas arqueológicas das terras baixas amazônicas (NIMUENDAJÚ, 1953; ROOSEVELT 1999; AMARAL, 2004-2011).

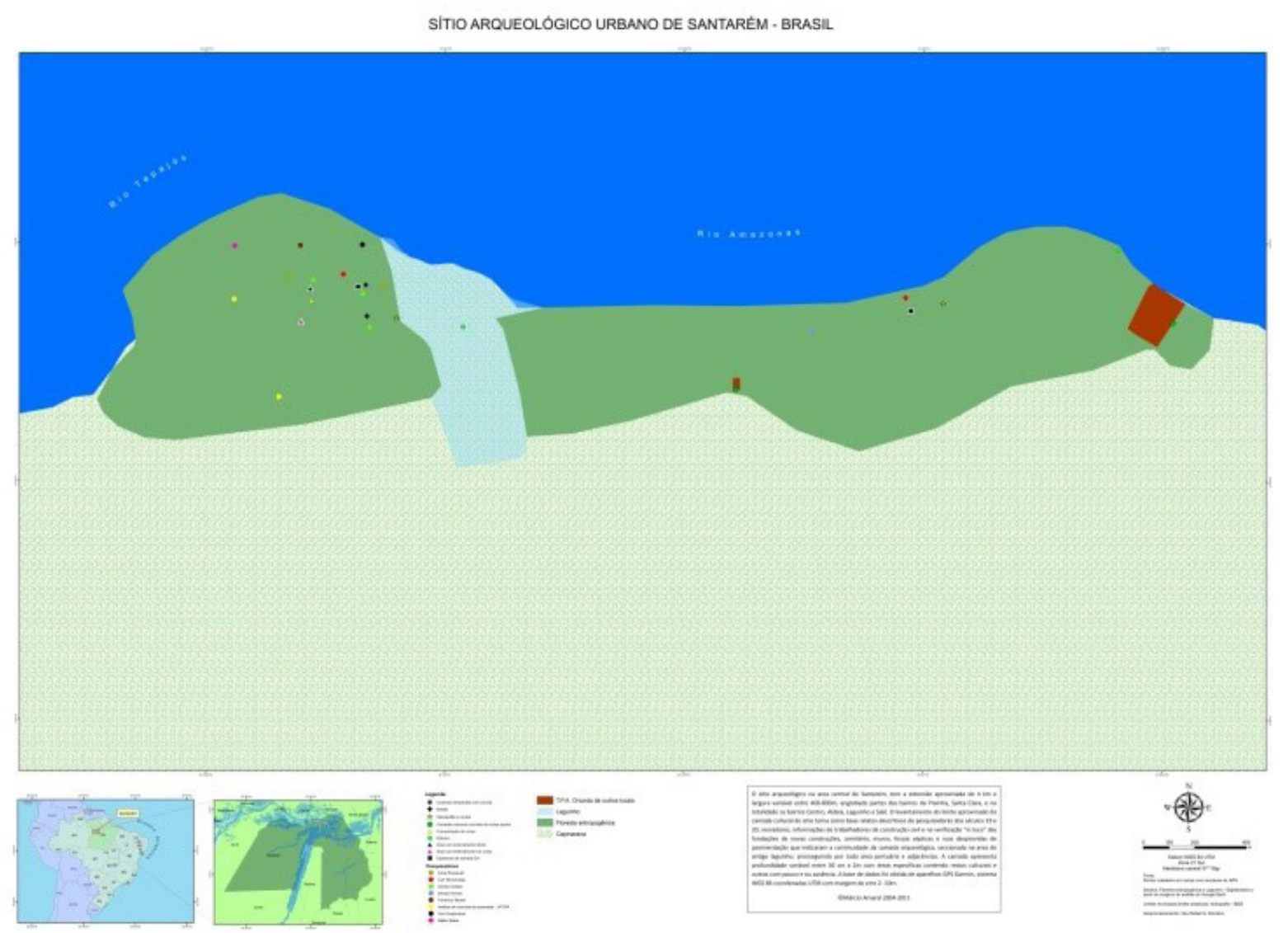

Figura 7 Mapa do sítio arqueológico urbano de Santarém. Márcio Amaral 2011.

Mapa elaborado por Rafael Monteiro. 
O desenvolvimento da pesquisa sistemática no sítio arqueológico Urbano de Santarém ocorre a partir da década de 1980 e incrementa-se entre 2000-2015. Isso favoreceu a aplicação de novas metodologias de campo, utilizando-se de sensoriamento remoto, geofísica e planialtimetria (ROOSEVELT, 1987; GUAPINDAIA, 1993; GOMES, 2011, SOUZA; 2012; SCHAAN E ALVES, 2015). Também auxiliaram no refinamento de escavações sistemáticas o processamento dos sedimentos em água e em peneiras múltiplas, com a curadoria feita em campo e em laboratório. (QUINN, 2004; MORAES et.al. 2013; SCHAAN E ALVES, 2015). Nos setores Aldeia e Sitio Porto, foi obtida uma série de datações que remetem ao período das ocupações Pocó ${ }^{8}$, culminando com as ocupações relacionadas à cultura Santarém Clássica:

Tabela 1- com datações nos setores: Sitio Porto de Santarém e Bairro Aldeia. Adaptado de Bruna Rocha (2017).

\begin{tabular}{|l|c|c|c|c|c|}
\hline \multicolumn{1}{|c|}{ Referências } & Ano & RC/TL/OLS & Sitio & Amostras & A.P. \\
\hline Alves & 2012 & RC & Porto & PSTM-006 & $3260 \pm 30 \mathrm{AP}$ \\
\hline Gomes & 2011 & $\mathrm{RC}$ & Aldeia & Beta 283902 & $3000 \pm 40 \mathrm{AP}$ \\
\hline Quinn & 2004 & $\mathrm{RC}$ & Porto & WK6836 & $2912 \pm 56 \mathrm{AP}$ \\
\hline Gomes & 2011 & $\mathrm{RC}$ & Aldeia & - & $2370 \pm 60 \mathrm{AP}$ \\
\hline Quinn & 2004 & $\mathrm{RC}$ & Porto & WK6834 & $2270 \pm 63 \mathrm{AP}$ \\
\hline Gomes & 2011 & $\mathrm{RC}$ & Aldeia & Beta 248485 & $2040 \pm 40 \mathrm{AP}$ \\
\hline Gomes & 2011 & $\mathrm{RC}$ & Aldeia & Beta 283903 & $1800 \pm 40 \mathrm{AP}$ \\
\hline Schaan \& Alves & 2015 & $\mathrm{RC}$ & Porto & & $1260 \pm 30 \mathrm{AP}$ \\
\hline Alves & 2012 & $\mathrm{RC}$ & Porto & PSTM-002 & $960 \pm 30 \mathrm{AP}$ \\
\hline Quinn & 2004 & $\mathrm{RC}$ & Porto & WK6844 & $664 \pm 57 \mathrm{AP}$ \\
\hline Quinn & 2004 & $\mathrm{RC}$ & Porto & WK6846 & $512 \pm 59 \mathrm{AP}$ \\
\hline Quinn & 2004 & $\mathrm{RC}$ & Porto & WK6841 & $425 \pm 56 \mathrm{AP}$ \\
\hline Quinn & 2004 & $\mathrm{RC}$ & Porto & WK6835 & $380 \pm 64 \mathrm{AP}$ \\
\hline
\end{tabular}

Em adição a esse panorama, dados complementares foram obtidos em áreas adjacentes da margem esquerda e no planalto Santareno/Belterrense, proporcionando o estabelecimento de uma cronologia preliminar para a região do baixo curso do rio Tapajós (GOMES, 2004; STENBORG et. al., 2012; ROCHA, 2017), projetando luzes na história pré-colonial e colonial da região de Santarém, demonstrando palimpsestos na paisagem (SHOCK, et. al., 2014), contendo em associação estratigráfica, indústria cerâmica e lítica diversificada, incluso objetos de pedras verdes em estágios diversos de manufatura.

Outro dado de relevância fornecido pela pesquisa arqueológica antiga e recente aponta a existência de pedreiras de arenito e de óxido de ferro, localizados em afloramentos a cerca de 5 quilômetros ao sul das antigas oficinas de produção lítica, identificadas no setor Sitio Porto de Santarém (HARTT, 1885; AMARAL, 2004; MORAES et al. 2014). O arenito da formação Alter-do-Chão funcionava como matéria prima base das indústrias líticas de Santarém, empregado inclusive na laminação e perfuração de pequenos blocos de óxido de ferro, utilizados na produção de rodas de fuso decoradas com incisões finas e pigmento vermelho.

8 Em trabalhos extensivos de campo ou associado a projetos de pesquisa, nos municípios de Belterra e Santarém, foram registrados sítios arqueológicos com cerâmicas Pocó. Localizados em áreas de terra firme, na região do planalto e margens do Tapajós (AMARAL, 2004; STENBORG. et. al.2010). 
A coleção arqueológica Juma Janaína ${ }^{9}$, oriunda em sua maior parte do sitio Porto de Santarém, apresenta artefatos cerâmicos e líticos - lascas de basalto, diábase, folhelho, silexito e pedra verde em diversos estágios de manufatura. Todavia, matérias-primas ígnea ou sedimentar silicosas, essenciais para manufatura de ferramentas, armas e muiraquitãs são inexistentes ou desconhecidas no entorno imediato de Santarém. Esse fato não impediu a sua aquisição em fontes distantes. O desenvolvimento de técnicas e de tecnologias inovadoras, claramente aplicadas às cadeias operatórias de produção de muiraquitãs, de ídolos de pedra de aspecto tridimensional e de contas líticas de pedras verdes, possibilitam classificar esses objetos como de origem local e marcadores culturais da área de Santarém (AMARAL, 2017).

\section{A IMPORTÂNCIA PANAMAZÔNICA DO MUIRAQUIT̃̃ E AS INTERAÇÕES SOCIAIS POR MEIO DAS PE- DRAS VERDES}

A importância das pedras verdes nas terras baixas amazônicas não se restringiu à área Santarém, pois também foram importantes na região da foz do rio Amazonas e na região da costa oriental amazônica, que liga a região ao nordeste do Brasil. Grupos Tupi controlavam não só importantes redes de troca de longa distância, como também as prováveis fontes de matéria-prima, bem como a produção e a distribuição dos objetos de pedras verdes conhecidos como tembetás (Holanda de Araújo, comunicação pessoal).

As redes de interação Tupi, nas quais circulavam os tembetás, e as redes controladas por grupos que produziam muiraquitãs no Baixo Amazonas, provavelmente Tapajó e Conduri, possuíam braços direcionados para a região do Salgado Paraense, rios Xingu e Tocantins, costa do Amapá e norte das Guianas que, por sua vez, conectavam-se com as Antilhas (NORONHA, 1768; DEVREUX, 1864; RICARDO, 2000; BOOMERT, 1987; DREYFUS, 1993).

As interações sociais por meio das redes de troca, na Amazônia, são bem conhecidas e seu alcance atingiu contextos geográficos ${ }^{10}$ de dimensões continentais. Todavia, a complexidade de interações que transitava por elas as tornaram pouco compreensíveis (BOOMERT, 1987; PORRO; 2006). No registro histórico há relatos de expedições regulares e alianças guerreiras entre os índios Tupinambá, da ilha de Upaon-açú (São Luis), e os seus aparentados do entorno de Belém, que tinham como finalidade o controle de fontes de silexito no baixo rio Tocantins (DEVREUX, 1864; NORONHA, 1768). E, provavelmente, uma das fontes de pedras verde, identificada em trabalhos de campo, no ano de 2011, está localizada nas proximidades de um dos tributários da margem esquerda daquele rio, distante cerca de $60 \mathrm{~km}$ ao sul do antigo povoado de Alcobaça, atual Tucuruí (AMARAL, s.d).

No baixo rio Tocantins, as ocupações Tupi são antigas e as datas mais tardias remontam a $950 \pm 70 \mathrm{AP}, 1550 \pm 70$ AD (SIMÕES e ARAUJO-COSTA, 1987; ROCHA, 2017; ALMEIDA e KATER, 2017), conferindo contemporaneidade em relação às ocupações tapajônicas na área Santarém, aldeias lacustres do Maranhão e, tardiamente, com as expedições de guerra Tupinambá, provavelmente iniciadas muito antes da ocupação francesa no Maranhão. Esses fatos dialogam com a

\footnotetext{
9 A relevante coleção arqueológica Juma Janaína, uma homenagem a minha filha, é composta por material cerâmico e lítico da cultura Santarém, resgatados em superfície em sítios arqueológicos na região de Belterra e Santarém (principalmente no setor sítio Porto de Santarém), entre os anos de 1982-2008. A salvaguarda, organização e estudo da coleção possibilitou ao autor, entre outras coisas, desnudar aspectos relacionados às cadeias operatórias de produção de muiraquitãs e antigas redes de interações sociais no baixo amazonas, contribuindo no aclaramento de questões espinhosas para arqueologia amazônica que se arrastavam desde o século XIX. Atualmente a coleção Juma Janaína encontra-se depositada sob a guarda do laboratório de arqueologia Curt Nimuendajú da UFOPA, cumprindo seu propósito de contribuir com o avanço do conhecimento arqueológico.

10 Escavações coordenadas por SCHAAN, ROOSEVELT E SILVEIRA, no biênio 2008-2009, na área 4b, trincheira 4, do sitio porto de Santarém, foi exumada em contexto de habitação provável, uma concha helicoidal oceânica em associação a cerâmicas tapajônicas (notas de campo não publicadas).
} 
ideia de fluxo multidirecional ${ }^{11}$ de pessoas, ideias, matérias-primas e produtos, inclusive na forma de muiraquitãs e cerâmicas, produzidas na área de Santarém e transportados para as regiões da costa setentrional e oriental amazônica, por meio das redes de interações sociais de curta, média e longa distância, como demonstrado no trabalho Gift of the Amazon, que assinala a presença de muiraquitãs na costa oriental brasileira (BOOMERT, 1987).

No início do século XX, no estado do Maranhão, as pesquisas conduzidas por Raimundo Lopes em aldeias lacustres resultaram no registro de um muiraquitã junto às estearias do rio Cajarí12 (LOPES, 1924; BOOMERT, 1987; NAVARRO, 2017). Na atualidade, o Laboratório de Arqueologia da Universidade Federal do Maranhão vem desenvolvendo a pesquisa acadêmica intitulada O Povo das Águas. Em trabalhos sistemáticos de campo, exumou-se um novo exemplar de muiraquitã na estearia de Boca do Rio (NAVARRO, et. al,. 2017:876-879). Todavia, o que nos chama atenção nos exemplares coletados no rio Cajarí e em Boca do Rio é os atributos iconográficos e tecnológicos diagnósticos dos muiraquitãs, produzidos na área Santarém.

As datas calibradas para um conjunto de seis aldeias lacustres situam essas ocupações do Maranhão entre os séculos 1X - Xll e os contextos associados ao muiraquitã das estearias de Boca do Rio 1065-995 A.P (NAVARRO et. al, 2017:874). As datas obtidas no sítio Porto de Santarém são 960 × 30 (ALVES, 2012a) 690-735 e A.P. 765-890 (SCHAAN e Alves, 2015). O cruzamento das datações permite inserir com segurança na mesma linha temporal, por meio de marcadores culturais sui generis da cultura Santarém, artefatos arqueológicos separados por milhares de quilômetros (Fig.8, 9, 10).

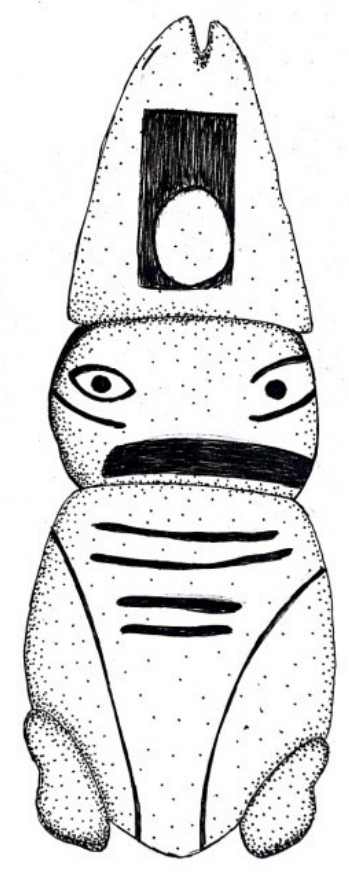

Figura 8 - Muiraquitã encontrado por Raimundo Lopes nas estarias do Rio Cajarí. Depositado no acervo do Museu Nacional. Vetorizado por Mayara Sá.

11 Em Arqueologia dos Tupi-Guarani, ALMEIDA (2016) aponta que a cerâmica da fase Tauá, na região do baixo Tocantins, contém elementos de convergência em relação às cerâmicas Tupi-Guarani, Inciso-Modeladas e Marajoara, configurando a região da foz dos rios Xingu-Tocantins como um dos ramos de interações sociais com fluxo permanente, ligando a região do baixo Amazonas com a costa setentrional e oriental Amazônica. 12

Raimundo Lopes foi o primeiro a propor a relação entre os muiraquitãs amazônicos e os encontrados por ele nas estearias do Maranhão. 


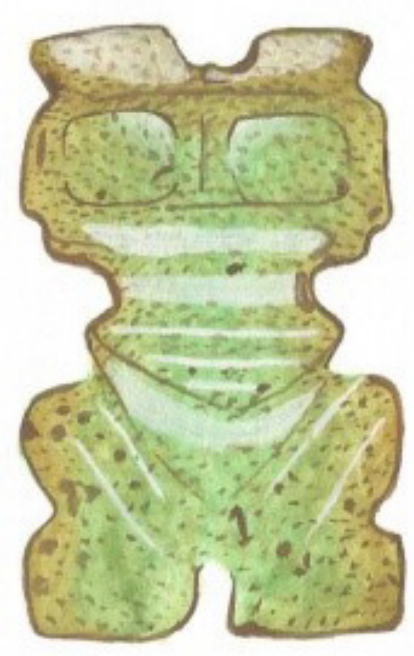

2:1

ANA

2018

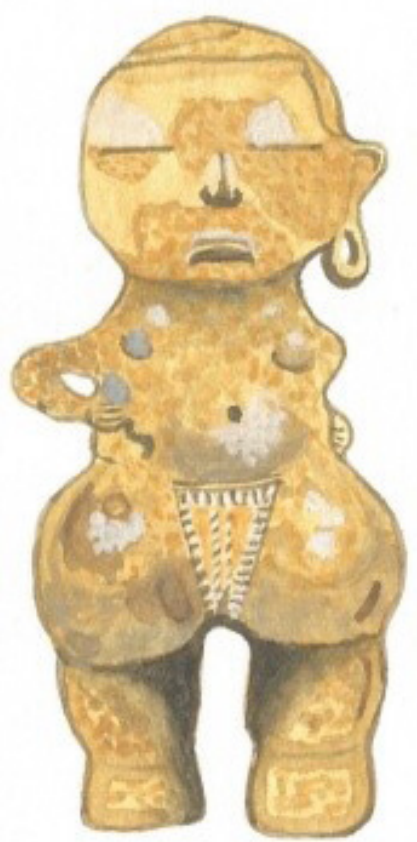

$1: 4$

ANA

2018

Figura 9 - Muiraquitã recuperado pelo laboratório de arqueologia da UFMA, nas estearias de Boca do Rio, e estatueta Tapajônica, pertencente ao acervo do Museu Nacional. Vetorizados por Ana Eugênia de Mendonça.

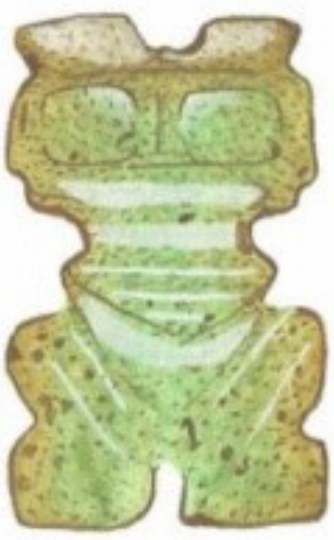

$2: 1$

ANA 2018

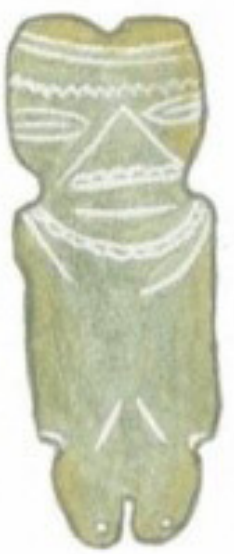

2:1

ANA

2018

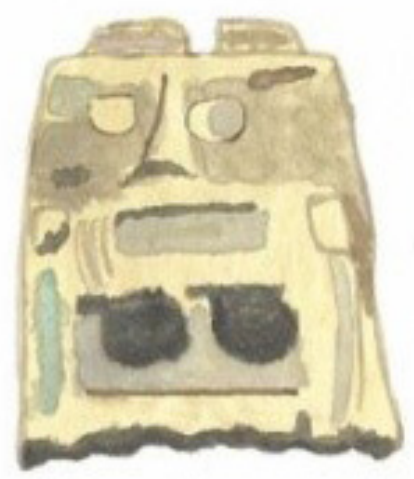

$1: 2$

ANA

2018

Figura 10 - Da esquerda para a direita, muiraquitã de Boca do Rio, estado do Maranhão, acervo UFMA. Muiraquitã e ídolo polimorfo da região de Santarém - Pará, depositados na coleção Emilio Goeldi. Chama atenção nos artefatos a decoração bipartida no topo da cabeça. Vetorizados por Ana Eugênia de Mendonça. 


\section{CONCLUSÃO}

Nem sempre a ecologia da paisagem tem assumido a devida importância para as pesquisas arqueológicas e etnológicas nas terras baixas amazônicas, que tradicionalmente foram direcionadas para a avaliação e a organização de traços da cultura material (KNAPP e ASHMORE, 1999). Contudo, os acréscimos de dados empíricos, nas últimas décadas, vêm alterando de maneira substancial o cenário arqueológico. Comprovando que as escolhas para instalação e permanência de grupos humanos na Amazônia pré-colonial e colonial, independente do ecossistema, eram precedidas de logística ameríndia, que provavelmente incluía o planejamento na sua instalação e manutenção, favorecendo o desenvolvimento de redes de interações das pessoas com seus ambientes (ANCHUETZ, et, al. 2001).

A relativa abundância de informações históricas relacionadas à ecologia de assentamentos, produção de bens de prestígio e interações sociais complexas, intra e extra área, Santarém esbarrava na ausência de base de dados arqueológicos que pudesse dar sustentação às crônicas. Essa problemática vem sendo contornada nas últimas duas décadas com a publicação de dados de pesquisa na região do Baixo Amazonas e, mais recentemente, na costa oriental amazônica, corroborando informações históricas e fornecendo os aportes necessários à elaboração perguntas e respostas, relacionadas à ecologia de assentamentos na área Santarém e interações sociais de longa distância na antiga Amazônia.

O entrecruzamento de comunidades ecológicas, na estratégica região da foz do rio Tapajós, é um caso interessante para a pesquisa arqueológica, pois o local onde estava localizada a maior urbe do sistema de chefia dos índios Tapajó, no século XVI (HERIARTE, 1874), constitui-se de extensa faixa arenosa, pouco recomendada para práticas agrícolas. Esse fato não impediu que uma área de aproximadamente quatro quilômetros quadrados fosse totalmente antropizada, transformando-se em terreno de solos altamente produtivos (BATES, 1979; NIMUENDAJU, 1953; AMARAL, 2011; SCHAAN E AMARAL, 2012).

O gatilho das transformações na paisagem, na área Santarém, no final do Pleistoceno - área que não dispõe de fontes de matérias-primas ígnea ou sedimentar silicosas apropriadas em seu entorno imediato - favoreceu o desenvolvimento e a manutenção de indústrias líticas na longa duração (LATHRAP, 1970). Não constituindo barreira para ocupações humanas em comunidades ecológicas diferenciadas, por milhares de anos, ou a construção de um pano social na longa duração, que culminou com o estabelecimento da cultura Santarém Clássica, por volta dos séculos V-VIII. Sociedade ameríndia que alcançou elevado nível sociocultural, espelhado na indústria cerâmica e lítica, com os afamados muiraquitãs lavrados em pedra verde. Esses itens e outros manufaturados em suportes perecíveis, de grande complexidade e beleza estética, foram desejados por povos de culturas e línguas diversas, assentados em pontos distantes das oficinas produção, na área Santarém (HERIARTE, 1874).

Abordagens recentes, voltadas para as transformações da paisagem e interações sociais antigas no Baixo Amazonas, têm resultado em avanços significativos para o conhecimento e discussão arqueológica nas terras baixas amazônicas. A publicação de resultados de pesquisas, realizadas no sítio arqueológico urbano de Santarém e na região do planalto Santareno/ Belterrense, projetou em dez séculos a duração e desenvolvimento da cultura Santarém Clássica e os Tapajós, seus expoentes máximos conhecidos, que encontram seu termo em meados do século XVIII; um dos desdobramentos da invasão europeia, no XVI (ALMEIDA SERRA, 1869 apud NIMUENDAJÚ, 1952). Contudo, sua influência sociocultural na longa duração ultrapassou os limites da baixa Amazônia e contextos associados e datados para muiraquitãs de estilo Santarém foram recuperados em aldeias lacustres no estado do Maranhão, possibilitando o estabelecimento de parâmetros temporais entre ecologias de assentamentos e cultura material distintas, separadas por milhares de quilômetros, ligadas por meio das complexas redes 
de interações sociais. Fornece ainda aportes significativos à pesquisa arqueológica, para o entendimento de problemáticas relacionadas à ecologia de assentamentos no baixo Amazonas, e de interações sociais ameríndias de longa distância. Tendo como pano de fundo paisagens étnicas e rituais, que, na longa duração, gestaram a cultura Santarém, concebendo padrões de ecologia de assentamentos humanos e redes de interações sociais milenares, sintetizadas na emblemática figura do muiraquitã, seguramente um dos mais importantes catalisadores sociais utilizados pelos Tapajós na propagação de suas ideias e ideologias, na Amazônia antiga.

\section{Agradecimentos}

Meus sinceros agradecimentos a Geórgea Layla Holanda de Araújo, Vanessa Eyng, Per Stenborg, Raimundo Cosme, Ellen Quinn, Claide de Paula Moraes, João Ayres, Ádria Gizelle Moraes, Arie Boomert, Ana Eugenia de Mendonça, Eduardo Kazuo Tamanaha, Fernando Ozório de Almeida, Natálya Pinheiro, Franciele Sá, Mayara Sá, João Cunha, Manoel Feliciano e José Marcião. 


\section{REFERENCIAS}

ACUÑA, Cristobal. Nuevo Descubrimiento Del Gran Rio de Las Amazonas. La Imprenta Del Reyno:Madrid, 1641. p.86.

ALMEIDA, Fernando. Arqueologia dos Tupi-Guarani no Baixo Amazonas. In: BARRETO, Cristiana, LIMA, Helena Pinto, e BETANCOURT, Carla Jaime (org). Cerâmicas arqueológicas da Amazônia: rumo a uma nova síntese. Belém: IPHAN - Ministério da Cultura, 2016. p. 171-182.

ALMEIDA, Fernando. The organics of settlement patters in Amazonia. Ancient Americas. $1^{\mathrm{a}}$ edição, Cidade: Routledge, 2017. pp. 278-311

ALMEIDA, Fernando., e KATER, Tiago. As cachoeiras como bolsões de histórias dos grupos indígenas das terras baixas sul-americanas. Revista Brasileira de História, [on line], vol. 37, n.75, 2017, p. 39-67.

ALVES, Rubana., LEVIS, Carolina., CLEMENT, Charles. Use and Management of Piquiá Suggest in situ Domestication along the Lower Tapajós River, Brazilian - New York: The New York Botanical Garden Press, 2016. p. 198-202.

ALVES, Daiana. Ocupação indígena na foz do rio Tapajós (3260-960 A.P.): estudo do sítio Porto de Santarém, baixo Amazonas. (Dissertação de Mestrado), Programa de Pós-graduação em Antropologia, Universidade Federal do Pará, Belém, 2012a. p. 227.

ALVES, Daiana. Arqueologia, história e a construção do passado Tapajó In: ARQUEOLOGIA, PATRIMÔNIO E MULTICULTURALISMO NA BEIRA DA ESTRADA: Pesquisando ao longo das Rodovias Transamazônica e SantarémCuiabá, Pará. Belém, GKNoronha, 2012b, p.11-17.

AMARAL, Márcio. Contextualização espacial, Histórica e Tecnológica dos Muiraquitãs Amazônicos. (Trabalho de conclusão de curso) Programa de Arqueologia, Universidade Federal do Oeste do Pará, Santarém, 2017. p. 130.

AMARAL, Márcio. Cerâmica Globular de Estilo Santarém. In: BARRETO, Cristiana, LIMA, Helena Pinto, e BETANCOURT, Carla Jaime (org). Cerâmicas arqueológicas da Amazônia: rumo a uma nova síntese. Belém: IPHAN Ministério da Cultura, 2016, p. 253-261.

AMARAL, Márcio. Levantamento Parcial do Sitio Andirobal e Inferência Sobre Conjunto Cerâmico. (Relatório de atividades de campo) Não publicado, 2004. p. 16.

AMARAL, Márcio. Notícias de campo, informes não publicados ou partilhados em projetos de pesquisa arqueológica de 2008 a 2012. Não publicado, 2012.

ANSCHUENTZ, Kurt. WILSHUSEN, Richard. SCHEICK, Cherie. Archaeology of Landscapes: Perspectives and Directions. Journal of Archeological Research. jstor.org, Vol. 9, 2001, p. 157-210.

BALÉE, William. The culture of Amazonian forests. In Resource management in Amazonia: indigenous and folk strategies. Advances in Economic Botany vol. 7. POSEY, D. A., BALÉE, W. (ed.). New York: New York Botanical Garden, 1989, p. 1-21.

BALÉE, William. Amazônia: Etnologia e História Indigena. (org.). Eduardo Viveiros de Castro e Manuela Carneiro da Cunha. São Paulo: FAPESP. p.385-393.

BALÉE, William. O Programa de Pesquisa da Ecologia Histórica. Cadernos do LEPAARQ. Tradução Rafael Milheira. Pelotas: Lepaarq, Vol. XIV, n²8, 2017, p.180-212.

BARBOSA, Rodrigues. Exploração e estudo do Valle do Amazonas - Rio Tapajós. Rio de Janeiro: Typographia Nacional, 1875. p. 151 .

BARBOSA, Rodrigues. O Muyraquitã - Manaus: Tip. do Amazonas, 1889.p.166. 
BATES, Henry. Um naturalista no rio Amazonas. Belo Horizonte: Itatiaia, 1979.p.300.

BERREDO, Bernardo. Annaes historicos do estado do Maranhão, em que se dá noticia do seu descobrimento, e tudo o mais que nelle tem succedido desde o anno em que foy descuberto até o de 1718: offerecidos ao augustissimo monarca D. João V. nosso senhor. Na Officina de Francisco Luiz Ameno, Impressor da Congragação Cameraria da Santa Igreja de Lisboa. MDCCXLIX, 748 páginas.

BETENDORF, Felipe. Chronica da Missão dos Padres da Companhia de Jesus no Estado do Maranhão. Revista do Instituto Historico e Geographico Brazileiro. Rio de Janeiro: Imprensa Nacional, 1910. p.683.

BOOMERT, Arie. Gifts of the Amazons: "green Stone" Pendants and Beads as Items of Ceremonial Exchange. In Amazonia and the Caribbean. St. Augustine: Press University of the West Indies, v. 67, n. 1, 1987, p. 33-54.

CAMPBELL, Jeremy. indigenous Urbanization in Amazonia: Interpretive Challenges and Opportunities. The Journal of Latin American and Caribbean Anthropology. online library, Volume 20, Edição 1, Março de 2015. p. 80-86.

CARVAJAL, Gaspar. Relação do novo descobrimento do famoso rio Grande. In: Gaspar CARVAJAL, Alonso. d. ROJAS, \& Cristobal. d. ACUNA, Descobrimento do rio das Amazonas. São Paulo: Cia Ed. Nacional, 1941 [1542]. p.294.

CLEMENT, R. Charles., FREITAS, Fabio. Domestication and Dispersal of Native Crops in Amazonia. Disponível em http:// repositorio.inpa.gov.br/handle/123/3885 2013. Acesso em 28/02/2018. 13:42

D’EVREUX, Yves. Voyage Dans Le Nord du Brésil. Leipzig e Paris: M. Ferdinand Denis, 1864. p.556.

Departamento Nacional da Produção Mineral. Projeto RADAMBRASIL. Folha AS.21 - Santarém: geologia, geomorfologia, pedologia, vegetação e uso potencial da terra. Volume 10. Rio de Janeiro, 1976.

DREYFUS, Simone. Amazônia: Etnologia e História Indigena. (org.). Eduardo Viveiros de Castro e Manuela Carneiro da Cunha. São Paulo : FAPESP.p.19-42.

OLIVEIRA, Raimundo., CORREA, João. Caracterização dos Solos da Área do Planalto de Belterra, Município de Santarém, Estado do Pará. Belém: Embrapa, 2001.p.55.

DENEVAN, William. A bluff model of riverine settlement in prehistoric Amazonia. Annals of the Association of America Geographers. Taylor e Francis Ltd : Milton Park, UK, 4, 1996, p. 654-681.

FARIAS, Eliane. Breve Abordagem de Alterações Geomorfológicas nas Confluências dos Rios Tapajós e Amazonas - Santarém / PA. Revista Geonorte. Periodicos. Ufam.Edu. Edição Especial, Manaus, V.2, N.4, p.243 - 249, 2012.

FONSECA, João. Contextualização Histórica e Análise Mineralógica do Material Lítico Polido do Acervo Arqueológico do Museu Goeldi. Relatório Final, 2011. Relatório final não publicado.

GRENAND, Pierre., GRENAND, Françoise. La côte d'Amapá, de la bouche del'Amazonie à la baie d'Oyapock, à travers la tradition orale Palikur. Boletim do Museu Paraense Emilio Goeldi. Belém: Nova série, Antropologia, vol. 3, $\mathrm{n}^{\circ}$ 1, 1987, p. 1-77.

GOMES, Denise. Cerâmica arqueológica da Amazônia. Vasilhas da Coleção Tapajônica MAE-USP, São Paulo, Edusp/ Fapesp/Imprensa Oficial do Estado, 2002. 355 p.

HARRIS, Mark. Sistemas regionais, relações interétnicas e movimentos territoriais - Os Tapajó e além na história ameríndia. Revista de Antropologia. São Paulo: USP, v. 58, nº 1, 2015. p. 33-68.

HARTT, Charles. Contribuição para a Ethnologia do Valle do Amazonas. Rio de Janeiro: Archivos do Museu Nacional, VI, 1885. p. 174. 
HECKENBERGER, Michael., RUSSEL, Christian., FAUSTO, Carlos,. TONEY, Joshua., SCHMIDT Morgan,. PEREIRA, Edithe., FRANCHETTO, Bruna,. KUIKURO, Afukaka. Pre-Columbian Urbanism, Anthropogenic Landscapes, and the Future of the Amazon. Science. sciencemag.org, vol. 321, Edição 5893, 2008, p. 1214-1217.

HERIARTE, Mauricio. Descripção do Estado do Maranhão, Pará e Corupá e Rio das Amazonas. Viena: Imprensa do Filho de Carlos Gerold, 1874. p. 84.

IRION, George., BUSH, Mark.,NUNES de MELO, José., STUBEN, Doris., NEUMANN,Thomas., MULLER, Gistavo., MORAIS de, Jader., JUNK, W. J. A multiproxy palaeoecological record of Holocene lake sediments from the Rio Tapajós, eastern Amazonia, Palaeogeography, Palaeoclimatology, Palaeoecology. Elservier, 2006, p. 523-535.

KNAPP, Bernard. e ASHMORE, Wendy. Archaeological Landscapes: Constructed, Conceptualized, Ideational. Malden, Massachusetts, USA. Blackwell Publishers Inc., 1999. p. 1-32.

LATHRAP, Donald. W. O Alto Amazonas. Lisboa: Editorial Verbo, 1970. p. 271.

LOPES, Raimundo. A civilização lacustre do Brasil. Boletim do Museu Nacional. Rio de Janeiro: Editora, vol. 1, nº 2, 1924, p. 87-109.

MCGRATH, David., MITRAUD, Sylvia. Uma estratégia para viabilizar o manejo comunitário dos lagos de várzea. Relatório Parcial Projeto Várzea. Brasília: WWF-Brasil / IPAM, 2000.

MIRANDA, Heloisa., BUSTAMANTE, Mercedes., e MIRANDA, Antonio. The Fire Factor: In: OLIVEIRA, Paulo. e MARQUIS, Robert (eds). The Cerrados Of Brazil: Ecology And natural History of a Neotropical Savanna. USA: Columbia University Press, 2003, p. 1-10.

MORAES, Claide., AMARAL, Márcio., e SANTOS, Rogério. Os artesãos das Amazonas: a Diversidade da Indústria Litica os Tapajó e o Muiraquitã. Actas del 3r Encuentro Internacional de Arqueología Amazónica. (Quito: Instituto Francés de Estudios Andinos), 2014, p. 133-40.

NAVARRO, Alexandre. Viviendo Sobre Ríos y Lagos: Los Palafitos Prehistoricos de Maranhão y su complejidad Social. Boletín Americanista, Universitat de Barcelona, año 1xvii, 2, n. ${ }^{\circ}$ 75, , págs. 17-32, 2017.

NAVARRO, Alexandre., COSTA, Marcondes., SILVA, Abraão., RÔMUlO, Angélica., RODRIGUES, Suyanne., GOUVEIA, João. O muiraquitã da estearia da Boca do Rio, Santa Helena, Maranhão: estudo arqueológico, mineralógico e simbólico. Boletim Museu Paraense Emílio Goeldi. Belém: ed. Humanas v. 12, n. 3, 2017, p. 869-849.

NEVES, Eduardo. Warfare in precolonial Amazonia: when Carneiro meets Clastres. In: NIELSEN, Axel. E., WALKER, William. Warfare in cultural context: practice, theory, and the archaeology of violence. Tucson: University of Arizona, 2009, p. 139-164.

NIMUENDAJU, Curt. Archaeological Researches in the Brazilian Guyana and in the Amazon Region. In STENBORG, Per. (ed). Pursuit of a Past Amazon: Etnologiska Studier 45. Gothenburg: Museum of World Culture, 2004, p. 390.

NIMUENDAJÚ, Curt. Os Tapajó. Revista de Antropologia. São Paulo, USP, vol. 1, nº 1, 1953, p. 53-61.

NIMUENDAJÚ, Curt. The Tapajó. Tradução: John Howland Rowe. The Kroeber Anthropological Society Papers. Berkeley, UK, n, 6, 1952, p. 1-25.

NIMUENDAJU, Curt. Os Tapajó, Boletim Paraense do Museu Emílio Goeldi. 1949. pp.93-106.

NORONHA, José. (1768). Roteiro da Viagem da Cidade do Pará, até as Ultimas Colônias do Sertão da Provincia. Belém:TYPOGRAFIA SANTOS \& IRMÃOS, 1862.

NORONHA, José. Introdução. In: Porro, Antonio. Posthumous Publication of J. M. Noronha's Roteiro da Viagem da Cidade do Pará até as Últimas Colônias do Sertão da Província [1768]. São Paulo: Edusp, 2006. 
OLIVEIRA, Josafá., PASTANA, José., NAVEGANTE, Paulo., SCHALKEN, George., Caracterização Hidrogeológica da Cidade de Santarém e das Vilas de Mojui dos Campos e Alter do Chão com Proposta Técnica para Perfuração de Poços tubulares profundos. abas.org, Paidéia, 16(34), 2000, p. 161-168.

PALACE, Michael., MCMICHAEL. Cristal., N. H. ,BRASWELL., Bobby., HAGEN, Scott., BUSH, Mark., NEVES ,Eduardo., TAMANAHA, Eduardo., HERRICK, Christina., FROLKING, Steve. Ancient Amazonian populations left lasting impacts on forest structure. Esajournals. Wiley On Line Library - Ecosphere, volume 8(12), 2017. p 1-19.

PALMATARY, Helen. The Archaeology of the Lower Tapajós Valley, Brazil. Transactions of the America Philosophical Society. Philadelphia: New Series, 50: p. 243, 1960.

PORRO, Antonio. Mercadorias e rotas de comércio intertribal na Amazônia. Revista do Museu Paulista, Nova Série 30, São Paulo: Editora USP, 1985, p. 1-13.

PORRO, Antonio. História indígena do alto e médio Amazonas, Séculos XVI a XVIII. In CUNHA, Manuela Carneiro (ed). História dos Índios no Brasil. São Paulo: Companhia das Letras/Secretaria Municipal de Cultura/FAPESP, 1992, p. 175-196.

PORRO, Antonio. Notas sobre o antigo povoamento indigena do alto Trombetas e Mapuera. Boletim do Museu Paraense Emilio Goeldi. Belém: Humanas, v.3 n.3, páginas 287 - 297, setembro/dezembro de 2008.

QUINN, Ellen. R. Excavating “Tapajó” ceramics at Santarém: their age and archaeological context. (tese de doutorado). Anthropology Department, University of Illinois, Chicago, 2004.p.292.

RICARDO, Carlos. (ed). Povos Indígenas no Brasil, 1996-2000. São Paulo: Instituto Socioambiental, 2000.

ROCHA, Bruna., VALLE, Raoni., MORAES, Claide., e NEPOMUCENO, Itala. Brazil: Day of Terror in Mato Grosso. Disponível em http://lab.org.uk/day-of-terror. 2013. Acesso em 13/12/2016.

ROCHA, Josan. F., Solos da região sudeste do Município de Santarém, estado do Pará: Mapeamento e Classificação. (Dissertação Mestrado) Programa de Pós-Graduação em Recursos Naturais da Amazônia, Universidade Federal do Oeste do Pará. Santarém, 2014.

ROCHA, Bruna. Ipi Ocemumuge: A Regional Archaeology of the Upper Tapajós River (Tese de doutorado). Institute of Archaeology, University College London, Londres, 2017. p. 620.

RODRIGUES, João. O Muiyraquitã e os Ídolos symbolicos. Rio de Janeiro: Imprensa Nacional, 1889. p.263.

ROOSEVELT, Anna. The development of prehistoric complex societies: Amazonia: a tropical forest, in BACUS, E. A. and LECERO, L. J. (ed) Complex Polities in the Ancient Tropical World.Brasil: Scielo, p. 13-33, 1999.

ROOSEVELT, Anna. Moradores da Caverna Paleoindiana na Amazônia: O Povoamento das Américas. Ciência 272. São Paulo: Fapesp Editora, páginas 373-384, 1996.

ROOSEVELT, Anna. Arqueologia Amazônica. In CUNHA, Manuela Carneiro (ed). História dos Índios no Brasil. São Paulo: Companhia das Letras/Secretaria Municipal de Cultura/FAPESP, 1992, p. 53-86.

ROSTAIN, Stephen. C'est curieux chez les Amazoniens ce besoin de faire des vases Alfareras Palikur de Guyana. In: BARRETO, Cristiana. LIMA, Helena. P., Lima and BETANCOURT, Carla. J. (eds.). Cerâmicas arqueológicas da Amazônia: rumo a uma nova síntese. Belém: IPHAN- Ministério da Cultura, 2016, p. 97-114.

ROSTAIN, Stephen. (éd.) Antes de Orellana. Actas del 3er Encuentro internacional de arqueología amazónica, Quito, 2014a.

ROSTAIN, Stephen. (éd.) Amazonía. Memorias de las conferencias magistrales del 3er Encuentro internacional de arqueología amazónica. Quito, 2014b. 
SIMÕES, Mário., ARAUJO-COSTA, Fernanda. Pesquisas Arqueológicas no Baixo Rio Tocantins - Pará. Revista de . Arqueologia. Belém: UFPA, 4 (1), 5 vi, 1987, p. 11-27.

SCHAAN, Denise., ALVES, Daiana. Um Porto, Muitas Histórias: Arqueologia em Santarém. Belém: Gráica Supercores, 2015.p.162.

SCHAAN, Denise., AMARAL, Anderson. Grande Expansão Geográfica dos Tapajó. In SCHAAN, D. Arqueologia, Patrimônio e Multiculturalismo na Beira da Estrada. Pesquisando ao Longo das Rodovias Transamazônica e SantarémCuiabá, Pará. Belém: GK Noronha, 2012, p. 17-36.

SCHAAN, Denise. ., ROOSEVELT, Anna. Curso Intensivo de Campo em Arqueologia Ambiental. Projeto Baixo Amazonas, Universidade Federal do Pará. $1^{\circ}$ Relatório Parcial. Não publicado, 2008.

SCHAAN, DENISE. Salvamento do sitio PA-ST-42: Porto de Santarém. Relatório Técnico. Universidade Federal do Oeste do Pará, 2010.

SILVA, Maria., SANTOS, Eron., SANTOS, J. M., LIMA, Maria., NASCIMENTO, Helson., FEIO, Bruno., SILVA, José. VIEIRA, Paulo., Diagnóstico e Planejamento de desenvolvimento do território Rural do Nordeste Paraense. SEPOF: Secretaria Estadual de Planejamento Orçamento e Finanças, 2005. p.133.

SOUZA, Daiane. GPR aplicado à arqueologia nas áreas do Porto da Cargill (Santarém/PA) e no Palacete Faciola (Belém/ PA) (Dissertação de Mestrado). Programa de Pós-Graduação em Geofísica, Universidade Federal do Pará, Belém, 2012.

STENBORG, Per. SCHAAN, Denise., FIGUEREDO, Camila. Contours of the Past: LiDAR Data Expands theLimits of Late Pre-Columbian Human Settlementin the Santarém Region, Lower Amazon. jstor.org, Journal of Field Archaelogy, 2018 , p. $44-57$.

STENBORG, Per. SCHAAN, Denise. AMARAL-LIMA, Márcio. Precolumbian land use and settlement pattern in the Amazon region, lower Amazon. Revista Amazônica. Belém: UFPA, 4 (1), 2012, p. 222-250.

STENBORG, Per. SCHAAN, Denise., Isendahl, Christian., SÖDERSTRÖM, Mats., Eriksson, Jan., AMARAL, Márcio., OLVMO, Mats. Cultivated Wilderness Project - Hinterland Archaeology in the Belterra Region, Pará, Brasil. In ROSTAIN, Stephen. (Ed). Antes de Orellana. Actas del 3er Encuentro Internacional de Arqueología Amazónica. 2014, p. 149-155.

SHOCK, Myrtle., MORAES, Claide., Belletti, Jacqueline., LIMA, Marjorie., SILVA, Francini., LIMA, Lígia., CASSINO, Mariana., LIMA, Ângela. Initial contributions of charred plant remains from archaeological sites in the Amazon to reconstructions of historical ecology. Actas del 3er Encuentro Internacional de Arqueología Amazónica, 2014, p. 201-206.

Recebido em: 19/06/2018

Aprovado em: 16/09/2018

Publicado em: 30/11/2018 